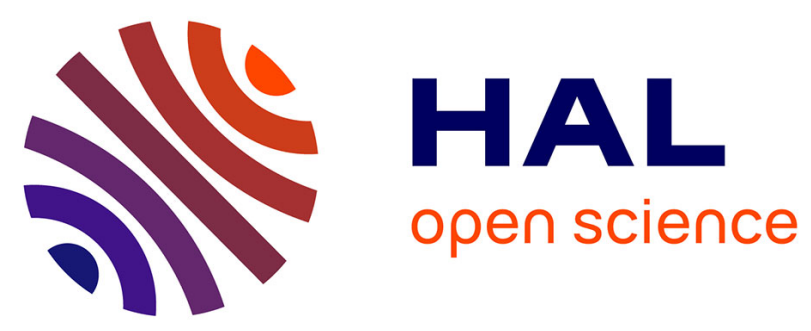

\title{
ELECTRON TRANSFER EFFECT IN INTRINSIC TELLURIUM SINGLE CRYSTALS
}

\author{
R. Asauskas, V. Balynas, Z. Dobrovolskis, A. Krotkus, W. Hoerstel
}

\section{To cite this version:}

R. Asauskas, V. Balynas, Z. Dobrovolskis, A. Krotkus, W. Hoerstel. ELECTRON TRANSFER EFFECT IN INTRINSIC TELLURIUM SINGLE CRYSTALS. Journal de Physique Colloques, 1981, 42 (C7), pp.C7-329-C7-334. 10.1051/jphyscol:1981740 . jpa-00221677

\section{HAL Id: jpa-00221677 https://hal.science/jpa-00221677}

Submitted on 1 Jan 1981

HAL is a multi-disciplinary open access archive for the deposit and dissemination of scientific research documents, whether they are published or not. The documents may come from teaching and research institutions in France or abroad, or from public or private research centers.
L'archive ouverte pluridisciplinaire HAL, est destinée au dépôt et à la diffusion de documents scientifiques de niveau recherche, publiés ou non, émanant des établissements d'enseignement et de recherche français ou étrangers, des laboratoires publics ou privés. 


\title{
ELECTRON TRANSFER EFFECT IN INTRINSIC TELLURIUM SINGLE CRYSTALS
}

\author{
R.. Asauskas, V. Balynas*, Z. Dobrovolskis,, A. Krotkus* and W. Hoerste1** \\ Kaunas Polytechnic Institute, Kaunas, USSR \\ *Institute of Semiconductor Physics, Academy of Sciences of the Lithuanian SSR, \\ Viinius, USSR \\ **Sektion Physik der Humboldt-Universität Berlin, Berlin, DDR
}

Résumé.- Des recherchea expérimentales et théoriques concernant le transfert des porteurg et les effets des porteurs chauds en tellure intrinsèque ont ets effectuees. Les caracteristiques courant - tension enregistrees au moyen de la technique des impulaions nanosecondes indiquent une resistance différentielle, ai l'intensité du champ dépasse une valeur de $3.5 \mathrm{kV} / \mathrm{cm}$.

A I'aide de sondes électriques des domaines mouvants de champs intengifs ont sté mis en éyidence.

Ia vitesse de derive monte $\mathrm{a} \cdot 10^{6} \mathrm{~cm} / \mathrm{s}$.

Le champ seuil et le coefficient de Hali ont ete mesures aux temperatures elevees et une pression hydrostatique. Les résultata indiquent $I^{\prime}$ existence d'une deuxieme bande de conduction, qui se trouve $0.26-0.38 \mathrm{eV}$ au-dessus de la premiere bande, et avec une mobilite des porteura relativement faible.

Les valeurs du champ seuil et de la mobilité slectronique, obtenues selon la methode Monte-Carlo, correspondent bien aux valeurs expérimentales..

\begin{abstract}
Experimental and theoretical atudies of charge transport and hot carrier effects have been made in intringic tellurium. Pulse meagurements of current-voltage characteristics have shown a negative differential resistance at fields above $3.5 \mathrm{kV} / \mathrm{cm}$. Moving high-field domains were observed by potential probe measurements. The velocity of the domain was $7.106 \mathrm{~cm} / \mathrm{s}$. Hydrostatic pressure measurements of threahold field and Hall coefficient were periormed at elevated temperatures, which suggest the existence of a second, low mobility conduction band located $0.26-0.38 \mathrm{eV}$ above the first one. Reasonable agreement was obtained between the measured magnitudes of threshold fleld and electron mobility and the regults of Monte Carlo calculations.
\end{abstract}

1. Introduction.- Semiconducting tellurium alwayg shows p-type conduction in the extrinsic range. Thereiore, the investigation of the conduction electron propertiea is posgible in the intringic conduction range only. Recent experimental investigations of high field transport in intrinaic tellurium shows that the current-voltage characteriatics exhibits a voltage-controlled negative differential resistance (n.d.r.) at fields above $3.5 \mathrm{kV} / \mathrm{cm} / 1 /$. The present work deals with a further examination of this effect. The measurementa of 
current-voltage characteristics and Hall effect were made under hydrostatic pressure to obtain information about the nature of n.d.r.. Monte Carlo calculations have also been carried out using the most probable values of parameters in order to explain the experimental results.

2. Sample preparation.- The amples investigated were cut from Te aingle crystals with a hole concentration of $5 \cdot 10^{14} \mathrm{~cm}^{-3}$ and a mobility of $5000 \mathrm{~cm}^{2} / \mathrm{Ve}$ at $77 \mathrm{~K}$ parallel to the c-axis. They were dumbbell shaped to eleminate the influence of electron extraction in the nearcathode region. The field distribution along the sample was measured using two gold wire potential probes. The first one was alloyed to the middle thin part of the sample. The voltage of this probe was the basic potential. The second wire was pressed to the sample at various distances from the alloyed probe.

3. Measurements at atmospheric pressure.- Fig. 1 shows current voltage characteristics measured under atmospheric pressure at various temperatures and $5 \mathrm{~ns}$ after pulse beginning. A voltage controlled

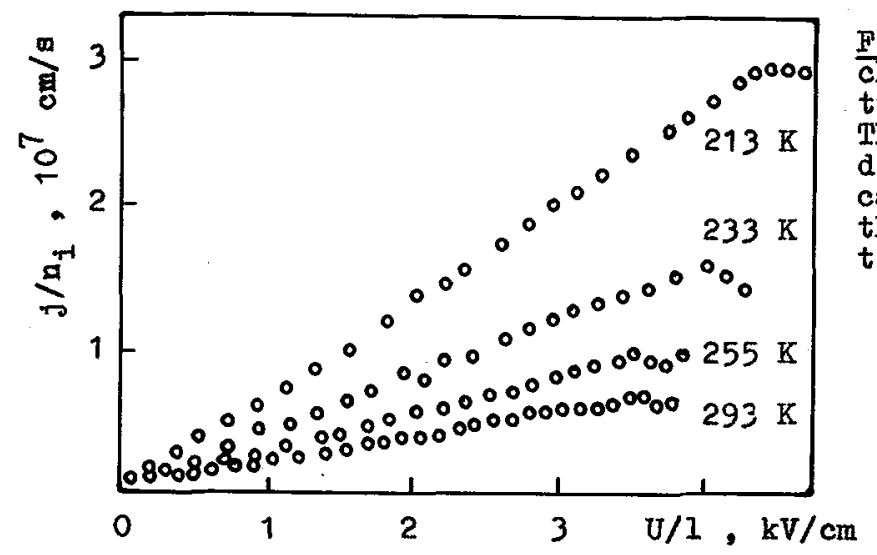

Fig. 1: Current-voltage characteristics of intringic tellurium sample. The current dengity is divided by the intrinsic carrier concentration at the corresponding temperature.

n.d.r. is observed at electric field strengths above $3.5 \mathrm{kV} / \mathrm{cm}$. It must be noted that no superohmic increase of the current was detected at fields below the threshold of n.d.r., which would be typical for impact ionization. The current pulses show a single kink as the field is just at the threshold. Oscillations can be observed on the growing current when the field is increased further. The n.d.r. exists in the intrinsic conduction range only. No n.d.r. was observed at $183 \mathrm{~K}$ where hole conduction prevails /1/. In / / it is shown that a high field domain is formed at the threshold of n.d.r.. We made potential probe measurements to establish the velocity of the domain. The po- 
tential pulses measured at $225 \mathrm{~K}$ are shown in fig. 2. The shape of the pulses shows that the high field domain propagates in the sample in the direction toward the anode with velocity of $7 \cdot 10^{6} \mathrm{~cm} / \mathrm{s}$. The direction of this propagation as well as the disappearance of n.d.r. at low temperatures in the hole conduction range gives evidence that the n.d.r. is connected with conduction electrono. The field and time range in which the instability is observed suggest that the most probable cause of this effect is an electron transfer to a higher lying conduction band. A claseical test for the electron transfer model is the hydrogtatic preagure experiment. Therefore, we made investigations under hydrostatic pressure up to $1500 \mathrm{MPa}$.

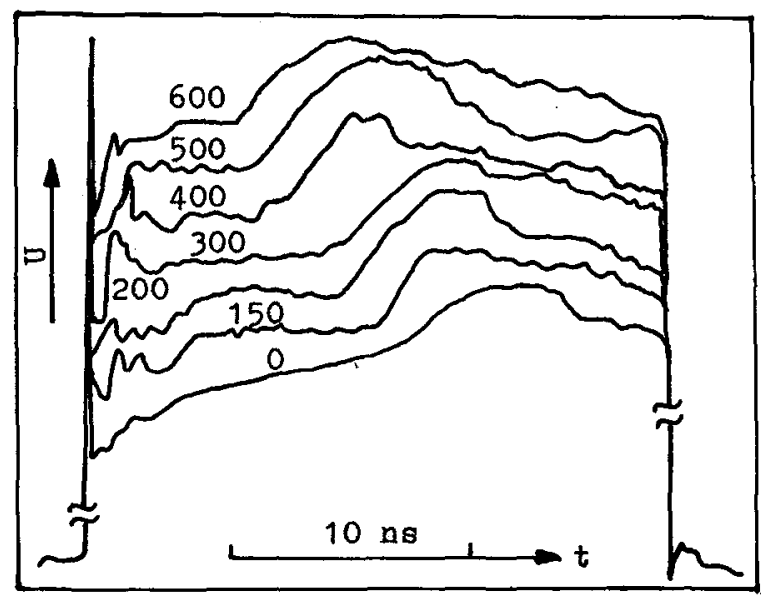

Fig. 2: Potential probe pulaes. The average field in the sample is $4.2 \mathrm{kV} / \mathrm{cm}$, the temperature of the measurement $223 \mathrm{~K}$. The distance from the basic probe towards the cathode is noted in micrometers.

4. Hydrostatic pressure measurementa.- Application of hydrostatic pressure changes the energy spectrum of electrons in the crystal and the occupation change of particular levels thus leads to an increase or decrease of the threshold field for intervalley transfer of hot electrons. For tellurium however neither the position of the second conduction band nor the pressure dependence of the interband aeparation are known. Therefore, it was necessary to determine at least the sign of the pressure coefficient from an independent experiment. We have measured the pressure dependence of the anomelous aign reversal in the Hall coefficient $/ 3 /$.

In tellurium the Hall coefficient shows a twofold aign reversal a the temperature increages: in the transition region from extrinaic to intrinsic conduction and at temperatures above $500 \mathrm{~K}$. The second aign reversal is explained in terms of the thermal occupation of a higher lying low-mobility conduction band at elevated temperatures $/ 2 /$. We have found in $/ 3 /$ that the invergion temperature $T_{i}$ decreases with 
increasing hydrostatic pressure. $T_{i}$ is equal to $475 \mathrm{~K}$ and $440 \mathrm{~K}$ at $500 \mathrm{MPa}$ and $800 \mathrm{MPa}$ reap.. This means that the interband separation which is proportional to $\mathrm{T}_{i} / 3 /$ decreaser under hydrostatic pressure. One can anticipate therefore a decrease of the threshold field for n.d.r. if the latter is caused by interband transfer of electrons.

The experimental deta presented in fig. 3 support this suggestion. As can be seen from fig. 3, the threshold field decresses under hydrostatic preasure. At preasures exceeding $1000 \mathrm{MPa}$ the current increases at fields below the n.d.r. threshold due to impact ionization. If this ionization is caused by electrons, one can estimate the interband separation at pressures where the ionization onset overtakes the n.d.r. threshold. The interband separation $\mathrm{E}_{12}$ at this

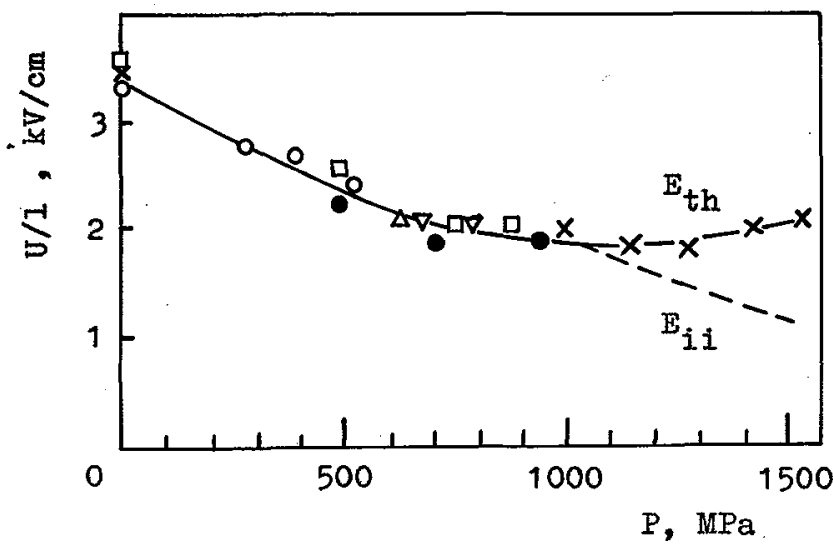

Fig. 3: Pressure dependences of the threshold fields for n.d.r. and impact ionization. The temperature of the measurement was 213 to $233 \mathrm{~K}$.

pressure must be equal to or greater than the ionization energy for an electron $E_{i}=E_{g}\left(2 m_{e}+m_{h}\right) /\left(m_{e}+m_{h}\right)$. The energy gap $E_{g}$ of tellurium at $1000 \mathrm{MPa}$ is equal to $0.175 \mathrm{eV} / 4 /$, which gives a value of $0.21 \mathrm{eV}$ for $\mathrm{E}_{i}$ and also for the minimum interband separation at this pressure. The pressure dependence of $\mathrm{E}_{\mathrm{g}}$ in tellurium is exponential /4/ due to the strong nonlinearity of compressibility; therefore, one can anticipate that the dependence of $\mathrm{E}_{12}$ has the same character. The extrapolation of $\mathrm{E}_{12}$ to atmospheric pressure with the alope obtained from the Hall-effect analysia /1/ gives a minimum value of $\mathrm{E}_{12}$ at atmospheric pressure of $0.26 \mathrm{eV}$.

Furthermore, because no impact ionization occurs at fielda below the n.d.r. threahold, the interband separation at atmospheric pressure muat be higher than $E_{1}$ for electrons. This gives $E_{12}=0.38 \mathrm{eV}$ as the maximum value for the interband separation at atmospheric pressure.

5. Honte Carlo calculationg - We made calculations of velocity-field characteriatics and of the low-field electron mobility at various 
lattice temperatures including some sets of band structure and scattering parameters. The low-field mobility was found from the calculated low-field diffusion constant. A two-level structure of the conduction band was assumed. An electron mass of $0.06 \mathrm{~m}_{0}$ was used in the lowest $\mathrm{H}$ valleys, calculations were performed both with a parabolic model and a two-band nonparabolic Kane model for the $H$ valleys. An analysis of galvanomagnetic effects in intrinsic tellurium shows that the effective mass must be ectremely high in the second conduction band. We have used a value of $10 \mathrm{~m}_{0}$ for $\mathrm{m}_{2}$ in our calculations. $\mathrm{E}_{12}=0.3 \mathrm{eV}$ was chosen. The following scattering mechanisms were taken into account: polar optical as well as optical and acoustical deformation potential interaction with phonons, and scattering by ionized centers with a concentration of $10^{16} \mathrm{~cm}^{-3}$. A comparison was made with the temperature dependence of electron mobility measured in /5/ and with the values of the threshold field for n.d.r.. A preliminary analysis shows that the agreement between measured and calcu-

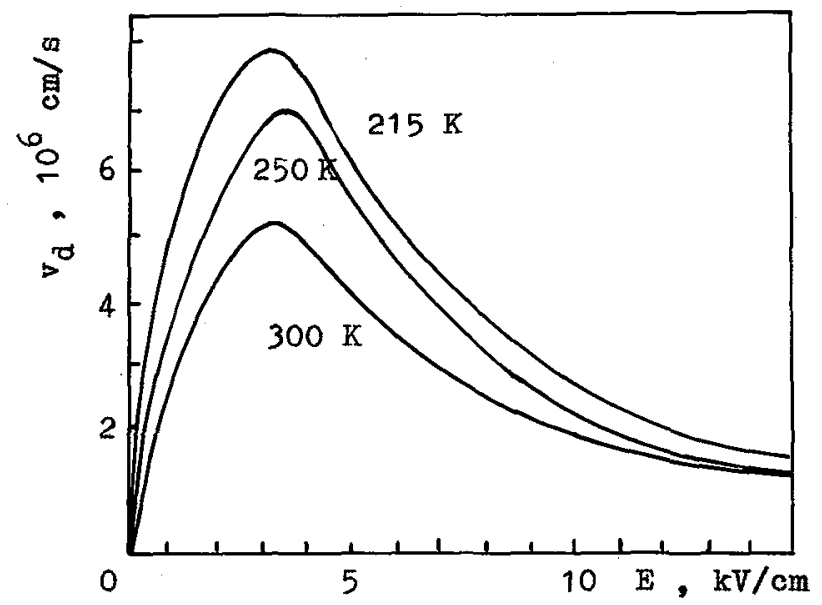

Fig. 4: Calculated field dependences of electron drift velocity at various lattice temperatures.

lated data is the best for the model including only a weak nonparabolicity of the $H$ bands (nonparabolicity constant $2 \mathrm{eV}^{-1}$ ) and dominant optical deformation potential scattering with a coupling constant of $10^{9} \mathrm{eV} / \mathrm{cm}$. In fig. 4 some velocity-field characteristics are shown calculated on the basis of this model. The calculations show that the electron transfer effect in teliurium ia characterized by a rather high peak-to-valley ratio of the drift velocitiea $v_{\text {peak }} / v_{\text {valley }}=5$ at $215 \mathrm{~K}$.

6. Conclusions.- N.d.r. and moving high field domains in intringic tellurium single crystals were observed. Invegtigations made under 
hydrostatic presgure have shown that the n.d.r. is due to electron tranefer into a second conduction ban lying at approximately 0.26 $0.38 \mathrm{eV}$ above the first one. Monte Carlo calculations predict a high peak-to-valley ratio suggesting that n-type tellurium would be a good material for effective Gunn oscillators.

Acknowledgement.- We are grateful to Prof. J. Pozela for helpful discusgions and support.

\section{References}

/1/ V. Balynas, Z. Dobrovolskis, W. Hoerstel, A. Krotkus, phys. stat. sol. (a) 62, K 9 (1980)

/2/ F. G. d.Ailion, C. H. Champness, Phys. Rev. B 11, 2205 (1975)

/3/ V. Balynas, Z. Dobrovoskis, W. Hoerstel, A. Krotkus, phys. stat. sol. (a) 64, K 115 (1981).

/4/ V. B. Anzin, M. I. Eremets, Y. V. Kosichkin, A. I. Madezhdinskii, A. M. Shirikov, phys. atat. 801. (a) 42, 385 (1977)

/5/ W. Hoerstel, Wiss. Z. Humboldt-Univergität, Math.-Nat. R. XXVII, 599 (1978) 